\title{
THE COMPARISON OF TWO TYPES COMPOSITE RESIN PACKABLE NANOHYBRID WITH TOTAL ETCH BONDING IN CLASS V RESTORATION MICROLEAKAGE
}

\author{
Sari Dewiyani \\ Department of Conservative, Faculty of Dentistry, \\ Prof. Dr. Moestopo (Beragama) University, Jakarta, Indonesia \\ Denissa Zahra S \\ Department of Conservative, Faculty of Dentistry, \\ Prof. Dr. Moestopo (Beragama) University, Jakarta, Indonesia \\ *Correspondence: saridewi.drg@gmail.com
}

\section{ARTICLE INFO}

Article History:

received: $21 / 06 / 2021$

revised: $21 / 08 / 2021$

accepted: $31 / 10 / 2021$

\section{Keywords:}

Packable composite resin, nanohybrid composite resin, class $\mathrm{V}$ restoration, total etch bonding, microleakage

DOI:

https://doi.org/10.32509/

mirshus.v1ii2.14

\section{ABSTRACT}

At dental clinic, there are some obstacles which occasionally may occur. A dentist runs out of the same brand of the composite resin and bonding material during tooth restoration, so they would have to be paired with material of the diffrent brand. Certain things that may occur during tooth restoration is polymerization shrinkage which forms a gap that could reducing edge density. This research is using packable nanohybrid type A composite resin and packable nanohybrid type B resin composite with total etch bonding on Class $V$ restoration with the thin cervical section of enamel. Aim: The aim of this study was to evaluate the differences between two types of packable nanohybrid composite resins with total etch bonding in Class V microleakage. Methods: This research used an experimental laboratory method with 32 maxillary premolars that have been prepared in Class V, which divided into 2 groups, group $\mathrm{A}$ and group B. Methylene blue will be used for the measurements, whereas the microscope to be used for the observation. Furthermore, the data were evaluated using the Mann Whitney U Test Method. Results: The research showed that there was a significant difference between group $A$ and group $B$, which is $p<0.05$. Conclusion: According to this research, it can be seen that group $B$ showed less leakage compared to group A.

\section{INTRODUCTION}

Dental and oral health is a part of body health related to others because oral health affects the overall body health. Many dental problems can interfere with health and damage aesthetics, one of which is cavities or dental caries. Dental caries is a disease of the hard tissue of the teeth caused by microorganism activity. The process of dental caries can be started with the presence of plaque on the surface of the teeth, it can come from sucrose (sugar) from food scraps that can also come from bacteria that stick to it and at any time it can turn into lactic acid which will lower the $\mathrm{pH}$ of the mouth, so that the enamel demineralization 
continues to become dental caries. The way to detect dental caries is to make it more recognizable, then grouping or classifying it.(Irianto et al., 2018)

The treatment to repair dental caries is filling the teeth or restorations. A restorative material that is often used and is able to restore dental function in chewing and aesthetics is composite resin.(Budimulia et al., 2018)

The advantages of composites are in the clinical manipulations, low heat transfer, long lasting for anterior teeth, insoluble in saliva, and tooth color. Composite resins can also be used in posterior teeth, as they are more abrasive resistance than glass ionomer cements and superior elasticity to amalgam. As technology advances, developing composite resins with a combination of two filler sizes such as microhybrid and nanohybrid types. The composite resins classification is based on manipulation, consisting of packable composite and flowable composite.(Anusavice et al., 2018)

A problem that often arises in composite resin restorations is polymerization shrinkage.(Anusavice, 1996) Burke and Qualthrough (1994) argue that shrinkage of polymerization can lead to the formation of gaps which can reduce edge density.(Siswadi et al., 1998) The gaps formed provide entry for bacteria and saliva and their components from the mouth, causing leakage of composite resin restorations edges.(Anusavice, 1996) Micro leakage can also be affected by the application of bonding. The bonding application consists of 2 systems, namely self etch and total etch. The use of self etch adhesive system is less sensitive than the total etch adhesive system.

Microleakage is defined as the microscopic gap between the cavity wall and the fill through which micro-organisms, liquids, molecules and ions can pass. These leaks can cause various conditions such as: secondary caries, tooth discoloration, hypersensitivity reactions, and can even accelerate the damage to the fill itself. Edge leakage occurs due to failure of the fill adaptation to the cavity wall.(Indriani, 2007)

In dental practice, problems often occur, such as when performing dental restorations, the composite resin or bonding material with the same brand runs out, so other brands are used, so this research was carried out in order to determine the quality of the fill against the edge leak. Based on the background explanation above, the researcher is interested in discussing to explain whether or not there are any differences in two types of packable nanohybrid composite resin with total etch bonding on the edge leakage of class $\mathrm{V}$ restorations.

\section{METHOD}

As this study involved human subjects, the Ethical Committee of Health Research from Universitas Prof. Dr. Moestopo (Beragama) has given permission for this study (146/KIP/FKGUPDMB/XI/2019).

The research will be carried out in November 2019 at the Conservation Laboratory of the Faculty of Dentistry, Prof. Dr. Moestopo.

\section{Types and Research Samples}

This type of research is a laboratory experimental research. The research sample used was permanent maxillary premolar teeth that had been extracted from several dental practices and public health centers in the Jakarta area which were collected from June to August 2019. The sample size was calculated using the Federer formula with the following calculations. [7]:

$(n-1)(t-1) \geq 15$

$(\mathrm{n}-1)(2-1) \geq 15$

$(\mathrm{n}-1) \geq 15$

$\mathrm{n}-1 \geq 15$

$\mathrm{n} \geq 16$

$\mathrm{n}$ : number of samples

t: number of groups

The minimum number of samples to be used in this study were 16 samples in each treatment group. The total sample used was 32 samples. 
Inclusion and Exclusion Criteria

The inclusion criteria in this study were: (1) extracted lower premolar teeth, (2) caries-free teeth, (3) teeth with intact enamel, and (4) teeth free of stains. While the exclusion criteria were: (1) Teeth that had been prepared but had penetrated the pulp, (2) Teeth that had been filled but were broken, and (3) Teeth that had been filled but changed color.

\section{Tools and Materials}

The materials used in this study were: (1) extracted maxillary premolar teeth, (2) packable nanohybrid composite resin type $\mathrm{A}$ (i-Dental), (3) packable nanohybrid composite resin type B, (4) ) Artificial Saliva, (5) OZERA clear nail polish, (6) Acetone, (7) $2 \%$ methylene blue solution, (8) $\mathrm{NaOCl}$ solution, (9) Scotchbond etchan etching, (10) 3M universal single bond, and (11) ) Red night.

The tools in this study were: (1) Strong 207 B micromotor, (2) Strong 207 B low speed contra angle handpiece, (3) Incubator, (4) 15x magnification microscope, HM-LUX 3, Portugal, (5) Bur round small, (6) Diamond Bur, (7) Standard tools, (8) Periodontal probe, (9) Elipar 1000 W LED (Light Emitting Diode), (10) Dappen glass, (11) Microbrush, (12) Separating Disc, and (13) Air sprays.

Procedure :

1. Sample Preparation:

a. Samples are checked to ensure compliance with criteria.

b. Before preparation, the entire crown was cleaned with $\mathrm{NaOCl}$ solution and divided into two types, type $A$ and type B.

c. All samples were prepared, Class V with a length of $3 \mathrm{~mm}$, a width of 3 $\mathrm{mm}$ and a depth of $2 \mathrm{~mm}$ on a bucoservical measured with a periodontal probe.

d. Apply the etching material and let stand for 15 seconds then the cavity is rinsed and dried. e. Followed by the application of generation $\mathrm{V}$ bonding over the etched tooth surface 1 smear, then irradiated for 10 seconds with a light cure.

f. Teeth that had been bonded were restored using composite resin type $\mathrm{A}$ and composite resin type $\mathrm{B}$ and then irradiated for 40 seconds.

g. Finishing using enhance.

2. Micro Leak Test Procedure with separation technique:

a. Both types were immersed in artificial saliva and stored in an incubator at $37^{\circ} \mathrm{C}$ for 24 hours.

b. After that, all surfaces of the teeth were smeared with two coats of nail polish except for the $1 \mathrm{~mm}$ area around the cavity edges and the apical part of the sample was coated with red wax.

c. Then the sample was immersed in a $2 \%$ methylene blue solution for 24 hours at room temperature.

d. Nail polish is removed using acetone

e. The tooth was cleaved sagittally in the center of the restoration using a separating disc.

f. Testing of data samples was done by looking at the tooth pieces using a $15 x$ magnification stereomicroscope

\section{Data Analysis}

Data analysis was performed using the non-parametric Mann-Whitney U test, which begins with the Shapiro Wilk normality test because this test is effective and valid for small samples ( $<50$ samples).

\section{RESULT AND DISCUSSION}

The study was conducted on 32 maxillary premolar teeth that had been extracted and prepared with a Class V cavity design then divided into 2 groups $(n=16)$, namely type $A$ and type $B$, filled with composite resin. packable nanohybrid type $A$ and packable nanohybrid composite resin type B using total etch bonding. The restoration edge leak test on the sample using a $15 \mathrm{x}$ magnification microscope. The 
results obtained were assessed by a scoring system with a score of 0-3. From the research conducted on the leakage edge of the packable nanohybrid composite resin type A and type B packable nanohybrid composite resin with total etch bonding, the results are shown in table 1.

Table 1. Edge leakage measurement results

\begin{tabular}{ccccc}
\hline Score & Nanohybrid & Percentage & Nanohybrid & Percentage \\
& Packable & & Packable & \\
& Composite & & Composite & \\
& Resin Type A & & Resin Type B & \\
\hline 0 & 1 & $6.25 \%$ & 8 & $50 \%$ \\
1 & 2 & $12.5 \%$ & 6 & $37.5 \%$ \\
2 & 4 & $25 \%$ & 2 & $12.5 \%$ \\
3 & 9 & $56.25 \%$ & 0 & $0 \%$ \\
\hline
\end{tabular}

Information:

0 : No penetration of methylene blue

1: The penetration of methylene blue reaches half of the cavity wall

2: The penetration of methylene blue exceeds half of the cavity wall but does not reach the axial wall of the cavity

3: Penetration of methylene blue covers all cavity walls including axial walls

From the table above, it can be seen that the type A group has 1 sample with a score of 0,2 samples with a score of 1.4 samples with a score of 2 and 9 samples with a score of 3.In the type B group has 8 samples with a score of 0.6 samples with a score 1,2 samples with a score of 2 and 0 samples at a score of 3 . The results of observations using a $15 \mathrm{x}$ magnification microscope were analyzed by the Mann Whitney U Test to see differences between all groups of restoration edge leakage. First, the normality test was conducted using the Shapiro Wilk test because this test was effective and valid for small samples $(<50$ samples). The results of the normality test with Shapiro Wilk can be seen in table 2 .
Table 2. Shapiro Wilk

\begin{tabular}{ll}
\hline Composite Resin & Sig. \\
\hline Type A & .001 \\
\hline Type B & .001 \\
\hline
\end{tabular}

Normality test results Shapiro Wilk on packable nanohybrid composite resin type $\mathrm{A}$ with packable nanohybrid composite resin type B, namely Sig. $<0.05$ so it can be said that the data are not normally distributed. Therefore, Mann Whitney U was used to test the analysis.

Table 3. Mann Whitney U

\begin{tabular}{ll}
\hline Composite Resin & p value \\
\hline Type A : Type B & 0.00
\end{tabular}

The results of the Mann Whitney U statistical test (Table 3) on packable nanohybrid composite resin type $A$ with packable nanohybrid composite resin type $B$ showed a value of $0.00(p<0.05)$ which means that there is a significant difference between packable nanohybrid composite resins. Type A and packable nanohybrid type $B$ with total etch bonding against edge leakage of Class $\mathrm{V}$ restorations. Therefore, there are similarities between the brand of composite resin and the brand of bonding issued by the same factory, so it affected to a better polymerization bond rather than using a composite resin with different bonding materials.

The results above indicate a significant difference between packable nanohybrid composite resin type $\mathrm{A}$ and packable nanohybrid composite resin type $\mathrm{B}$. This difference is indicated by the $p$ value obtained from the results of the Mann Whitney Test analysis, which is 0.00 less than the $\mathrm{p}$ value of 0,05 . The packable nanohybrid composite resin used in this study is type A and type B, the packable 
nanohybrid composite resin type $\mathrm{A}$ is a composite resin that is relatively inexpensive and rarely used in dental practice while the packable nanohybrid composite resin is a type of $\mathrm{B}$ is a commonly used and easier to obtain composite resin. The bonding used in this research is universal bonding from $3 \mathrm{M}$ because it is issued by the same factory as one of the packable nanohybrid composite resins studied; besides this bonding is easier to get. Class V GV Black which extends to both dentin and cementum is very critical, because the enamel on the cervix is so thin that etching causes many problems.(Irianto et al., 2018)

According to Lee et al (2007) in their study entitled "Influence of cavity dimension and restoration methods on the cusp deflection of premolars in composite restoration", composite resins used in dental restorations have shown that shrinkage occurs less than 1-6\% depending on the application technique, composition, and light curing process (Lee at al., 2007). According to Arias et al (2004), there is no bonding agent that can completely eliminate edge leakage. The causes of edge leakage are usually related to polymerization, shrinkage, composite resin used, chewing load, location of prepared margins and insertion technique used.(Arias et al., 2004)

Thus the hypothesis of this study is accepted, namely that there is a significant difference between packable nanohybrid composite resin type $\mathrm{A}$ and packable nanohybrid type B with total etch bonding to edge leakage Class V restorations.

\section{CONCLUSION}

There was a statistically significant difference between packable nanohybrid composite resin type $\mathrm{A}$ and packable nanohybrid composite resin type $\mathrm{B}$ using total etch bonding with $\mathrm{p}<0.05$.
Based on research results explanation, the researchers put forward several suggestions for further research in order to achieve better results, such as: (1) Using composite resin and the same bonding material so that edge leakage is minimal, and (2) to use the same brand of composite resin and bonding materials when performing restorations.

\section{REFERENCE}

Anusavice, K. J. (1996). Textbook of Dental Materials Science. Ed 10. trans. Lilian Juwono, Jakarta: EGC, 227-250

Anusavice, K. J., Shen, C., Rawls, H. (2012). Phillip's science of dental materials. Ed 12. St. Louis: Elsevier, 80-82

Arias, V. G., Campos, I. T., Pimenta, L. A. F. (2004). Microleakage study of three adhesive systems. Braz Dent J, 15(3), 194-198

Budimulia, B., Aryanto, M. (2018). Microleakage of Flowable Bulkfill Composite Resins at Various Irradiation Distances. J Ked Gi Unpad, 30(1), 1-7

Indriani, D. J. (2007). Resin Composites in Esthetic Dentistry. Jakarta: FKG University of Indonesia, 827-828

Irianto, D., Dewi, C., Fitriani, D. (2018). Classification of Dental Caries Disease Using a Combination of K-Nearest Neighbor and Genetic Algorithms. Journal of Information Technology Development and Computer Science, 2(8), 2926-2932

Lee, M. R., Cho, B. H., Son, H. H., Um, C. M., Lee, I. B. (2007). Influence of cavity dimension and restoration methods on the cusp deflection of premolars in composite restoration. Dent Mater. 23, 288-295

Syahdrajat, T. (2019). Research Guide for Medical and Health Thesis. Jakarta: CV Sunrise, 43-46

Siswadi, Y. L., Iskandar, B. (1998). Appropriate Application of Composite Recipes. MI Ked Gigi FKG Usakti, 14(38), 95-10 